\title{
A natureza dialógica e argumentativa do discurso interior revelada em interações em sala de aula de língua inglesa ${ }^{1}$
}

\author{
The dialogical and argumentative nature of inner discourse as revealed \\ in English language teaching classroom interactions
}

\author{
Karin Quast ${ }^{2}$ \\ Universidade de Taubaté - Taubaté - São Paulo - Brasil
} $\diamond$

\begin{abstract}
Resumo: Neste trabalho analisamos um modo de acontecer da linguagem geralmente desconsiderado, tido como algo marginal, mas que por vezes 'escapa' em eventos intersubjetivos: a fala privada. Esta é frequentemente concebida como sendo monológica e é analisada com enfoque na autorregulação, obscurecendo-se sua plurifuncionalidade e mantendo a dicotomia interno/externo, privado/social contrárias ao pensamento de Vygotsky (que, como Bakhtin, considera a dialogicidade constitutiva da linguagem, visto conceber a consciência enquanto drama). Analisando interações em sala de aula de língua inglesa, utilizando o paradigma indiciário e a análise micro-genética, encontramos pistas para os diferentes interlocutores e vozes presentes nesses enunciados. Assim, os estudos do Círculo (além da Teoria Polifônica da Enunciação e dos trabalhos de Authier-Revuz) permitem redimensionar a compreensão da fala privada, revelando tanto sua dialogicidade como sua natureza argumentativa, o que pode contribuir para que melhor compreendamos a dialogicidade/argumentatividade de todo enunciado e também do processo de construção de conhecimento.
\end{abstract}

Palavras-chave: Ensino-aprendizagem de língua estrangeira; Fala privada; Dialogismo; Argumentatividade do discurso interior

\begin{abstract}
In this paper we analyze a language 'phenomenon' which is not normally considered in studied about classroom interaction, being considered as marginal: private speech, which sometimes 'escapes' in these intersubjective events. Analyzing interactions in English language teaching classes, using the evidential paradigm and the micro-genetic analysis, we found hints of the different interlocutors and voices present in such utterances. Private speech is normally analyzed as being monologic and the focus is on self-regulation, obliterating its pluri-functionality and marking the internal-external distinction, maintaining the social/private dichotomy, which does not reflect Vygotsky's thought (who, as Bakhtin, considers the constitutive dialogicality of language when conceiving consciousness as a drama). It is the studies of the Circle of Bakhtin, then, (besides Ducrot's Poliphonic Theory of Enunciation as well as Authier-Revuz's work) that allow us to understand another dimension of private speech, reveiling not only its dialogicality but also its argumentative nature.
\end{abstract}

Keywords: Foreign language teaching-learning; Private speech; Dialogism; Inner speech argumentativeness

\footnotetext{
${ }^{1}$ Este artigo é um recorte de nossa tese de doutorado, que teve o apoio da FAPESP.

2 Possui graduação em Letras pela Universidade do Vale do Paraíba (1980), Mestrado em Linguística Aplicada pela Universidade de Taubaté (2003) e Doutorado em Educação pela Unicamp (2009). Atualmente atua no programa de Mestrado em Linguística Aplicada e no curso de Especialização em Língua Inglesa da Universidade de Taubaté (UNITAU). Atua principalmente nos seguintes temas: ensino/aprendizagem de línguas estrangeiras sob a perspectiva histórico-cultural e enunciativo-discursiva de linguagem; fonologia da língua inglesa; teorias de ensino/aprendizagem; abordagens e métodos de ensino de língua estrangeira; discurso interior; afetividade e aprendizagem de línguas; jogos e gamificação de conteúdo.
} 
O ponto de partida desta investigação foi a constatação de que nem todos os enunciados em sala de aula se dirigem ao professor ou colega(s), mas parecem ser dirigidos ao próprio sujeito. Intrigados com esse 'fenômeno', buscamos investigar esse 'falar consigo mesmo', ou seja, o que primeiramente Piaget (1999) conceituou como a fala egocêntrica, ou o "falar para si mesmo". Porém, Piaget enfatiza a falta de descentramento, de capacidade de alterar a perspectiva mental, a indiferenciação eu-outro, não conseguindo, pois, se colocar na posição do outro, nem tentando agir sobre ele. Essa fala não possuiria uma função social e iria se 'atrofiando' até então desaparecer no período das operações concretas. Ele não examina, como Vygotsky, justamente sua função no acompanhamento das ações.

Vygotsky tece várias críticas a Piaget, considerando que tal fala possui uma função extremamente importante no desenvolvimento infantil, pois "está a serviço da orientação mental, da compreensão consciente; ajuda a superar dificuldades" e está intimamente relacionada ao pensamento (VYGOTSKY, 1987, p. 166). Sendo o "ponto de encontro" entre os planos inter e intrapsicológico, é responsável pelo planejamento, direcionamento, monitoração, autorregulação, reelaboração, (re)estruturação do pensamento, autorreflexão etc., além de servir, às vezes, para descarga emocional. Entretanto, ela não desaparece pós a infância, representando, para o adulto, o "pensar para si próprio", podendo surgir como enunciados audíveis, monólogos encobertos ou fala interna condensada (VYGOTSKY, 1987, p. 22).

Cabe salientar que, embora Vygotsky considere a linguagem interior como monológica (por não haver ali um interlocutor fisicamente presente), ele ressalta que nos relacionamos com nós mesmos da mesma forma que nos relacionamos com os outros (VYGOTSKY, 2000[1929]), sendo o individual ou pessoal "uma forma superior de sociabilidade". Retomando Marx, como o faz Bakhtin/Voloshinov em O Freudismo (2001[1927], p. 3), Vygotsky afirma que o homem é "o conjunto de relações sociais, encarnado no indivíduo"; "Eu sou a relação social de mim para comigo mesmo".

Como então compreender esse diálogo do sujeito consigo mesmo, denominado de fala privada (FP), no campo de SLA (Second Language Acquisition) e que emerge em situações em que enfrentamos problemas, obstáculos, dúvidas? Temos um sujeito que se desdobra em dois: locutor e interlocutor. Esse desdobrar já foi apontado por Benveniste (2006[1974], p. 87-88) ao afirmar que a estrutura do diálogo é fundamental a toda enunciação e que o "monólogo", enquanto procedente da enunciação, é uma "variedade do diálogo". O monólogo, sendo, portanto, um diálogo interiorizado, não pode prescindir de um interlocutor, mesmo que este seja o "eu ouvinte", cuja "presença é necessária e suficiente para tornar significante a enunciação do eu locutor" e que, por seu turno então interpela o locutor. Segundo o autor, a própria língua permite que o locutor se desdobre em dois, assumindo dois papéis, pois na medida em que eu instauro o "eu", instauro também o "tu".

Vygotsky (2000[1929]) também cita a pessoa dual, o Homo duplex, ao se referir à personalidade como drama, ou seja, as funções psicológicas são "um agregado de relações sociais encarnadas no indivíduo"; as relações sociais estão condensadas em uma só pessoa, constituindo as funções psicológicas e o sujeito. Mas não é mero desdobramento do 'eu'. Os papéis e posições são diferentes, a relação é diferente. $\mathrm{O}$ indivíduo vivencia, pois, no plano intrapsicológico, a mesma categoria (o mesmo modo de ação social), que envolve várias funções mentais e a multiplicidade de perspectivas, de sistemas de referência, que se entrechocam.

Contudo, a maioria das pesquisas em SLA, mesmo quando embasadas em Vygotsky, a consideram como um monólogo (ou seja, há ali uma só voz), ignorando sua origem e orientação social, apagando o embate de vozes ali presente. A FP é tida como mero recurso mediacional, com foco nos processos de autorregulação e cognitivos. A concepção de linguagem é geralmente instrumental, mera ferramenta para a comunicação, servindo aos processos cognitivos e tida como dada, pronta, acabada, transparente. A questão da significação, central na obra de Vygotsky, é esquecida. O sujeito, por sua vez, é considerado como uno, autocentrado. Mas se o desenvolvimento das funções psicológicas superiores se dá a partir da conversão das relações intersubjetivas, da conversão de atividades externas em atividades internas, como então o outro desaparece? Buscamos, portanto, algumas respostas nos trabalhos do Círculo para compreender essa fala que se apresentava não como um monólogo ou mero diálogo, mas como dialógica, polifônica e argumentativa.

\section{Discurso interior e dialogismo}

Discordando, pois, de uma visão dicotômica (interno/ externo, privado/social, eu/outro) e da compreensão da fala privada enquanto ato individual, solitário, são os trabalhos do Círculo, em especial sobre o discurso interior, que sustentam nossa discussão sobre a dialogicidade fundante da FP (e do funcionamento mental).

Podemos compreender a dialogicidade como possuindo várias 'dimensões' porque: (1) todo dizer orienta-se pelo "já-dito", responde a outros enunciados e faz parte do "grande diálogo"; (2) todo enunciado é orientado a uma resposta, não somente porque a aguarda, mas pela própria antecipação da réplica, que, portanto, o 
condiciona; (3) há uma dialogia interna, ou seja, devido ao enunciado ser heterogêneo, por estar já povoado por outras vozes, por ser o ponto de encontro entre diferentes vozes sociais, diferentes perspectivas (ou quadros axiológicos).

Peytard (1996, p. 10) argumenta que a compreensão do discurso interior é essencial para a elaboração do dialogismo, aparecendo em várias obras do Círculo. Bakhtin/Voloshinov (2001, p. 18) afirmam que este acompanha cada ato consciente do homem bem como todo tipo de criação ideológica, todo ato de interpretação e compreensão (BAKHTIN, 1999, p. 37-38). Voloshinov (1926) menciona o discurso interior ao discutir o estilo do poeta, afirmando que o estilo nasce de seu discurso interior (é um trabalho com e entre as palavras interiorizadas), que, por sua vez, é produto de sua vida social, de seu grupo social. O grupo social é, pois, colocado como participante permanente do discurso interior (e exterior), ou como um auditor, representando a autoridade que exerce sobre nós. Assim, todo ato de consciência (que já é discurso interior), as palavras, a apreciação entonativovalorativa são já um ato social. Produto da comunicação social, a consciência é, pois, ideológica.

O fato é que nenhum ato consciente de algum grau de nitidez pode existir sem a fala interior, sem palavras e entoações - sem avaliações, e, conseqüentemente, todo ato consciente já é um ato social, um ato de comunicação. Mesmo a mais íntima autoconsciência é uma tentativa de se traduzir no código comum, de se avaliar de outro ponto de vista, e, conseqüentemente, vincula a orientação para um ouvinte possível. (VOLOSHINOV, 1926, p. 23)

Ao se abordar a consciência, a "alma individual", afirma Bakhtin (2001, p. 79-80), interpreta-se incorretamente um fenômeno que é, na verdade, social. O conteúdo do psiquismo é totalmente ideológico, pois nos é dado pelo meio objetivo da palavra: "a realidade do psiquismo interior é a do signo" (BAKHTIN, 1999, p. 49). Mesmo a ideia mais vaga pressupõe um convívio social organizado. Bakhtin (2001, p. 79-80) enfatiza, assim, aspectos que vemos também em Voloshinov (1981). As próprias escolhas linguísticas e a entonação são expressão da relação entre os interlocutores, do ambiente social em que o evento ocorre, do grupo social a que pertencem.

O discurso interior, ressalta Bakhtin (2001, p. 80), "também pressupõe o ouvinte eventual, constrói-se voltado para ele". Ele é dialógico, atravessado pelas avaliações de um ouvinte virtual, de um auditório potencial, ainda que este não esteja claro (VOLOSHINOV, 1981, p. 294). As raízes da autoconsciência encontramse no ambiente social. "Ao tomar consciência de mim mesmo, eu tento como que olhar para mim pelos olhos de outra pessoa, de outro representante do meu grupo social, da minha classe" (BAKHTIN, 2001, p. 86). É, pois, "nos laços sociais mais amplos", que "se elaboram todos os elementos do conteúdo e as formas dos nossos discursos interior e exterior, todo o acervo de avaliações, pontos de vista, enfoques etc. [...]". Tudo o que está relacionado à minha consciência provém do exterior e nela penetra pelas palavras de outros, contendo suas entonações e valores (BAKHTIN, 2000, p. 378).

Portanto, se o conteúdo do psiquismo é o signo ideológico, que é sempre interindividual e sendo a palavra "um drama com três personagens" - locutor, interlocutor e as outras vozes que soam naquela palavra (BAKHTIN, 2000, p. 350) -, não é possível conceber a FP como um monólogo. Para compreender o que é dito, é preciso examinar esse diálogo entre os personagens. Nossas palavras são sempre habitadas pelas palavras de outrem. E há já, na palavra, um embate entre posições sociais e ideológicas (BAKHTIN, 1999, p. 66); existem aí outras vozes, por vezes conflitantes. Entretanto, Bakhtin (2000, p. 350) adverte contra a concepção reducionista ou estrita de dialogismo enquanto discussão, polêmica, controvérsia, discordância, refutação. A concordância, destaca Bakhtin, é uma das formas mais importantes de dialogismo, pois "é rica em diversidade e matizes" (ibid., p. 354) e "pode manifestar-se por um único som, revelarse por uma única palavra [...]”. As relações dialógicas, no entanto, não se estabelecem unicamente entre enunciados, mas também em relação a nosso próprio enunciado e até palavras isoladas quando consideradas

[...] como signo da posição semântica de um outro, como representante do enunciado de um outro, ou seja, se ouvirmos nela a voz do outro. [...]. Por último, as relações dialógicas são possíveis também com a sua própria enunciação como um todo, com partes isoladas desse todo e com uma palavra isolada nele, se de algum modo nós nos separamos dessas relações, falamos com ressalva interna, mantemos distância face a elas, como que limitamos ou desdobramos a nossa autoridade (BAKHTIN, 2002, p. 184).

Contudo, um enunciado não se relaciona apenas com os que o precederam, mas também com os que o sucederão; ele é elaborado em função de uma reaçãoresposta, está voltado a um destinatário, de quem aguarda uma compreensão responsiva ativa, levando em conta, pois, seu fundo aperceptivo. Mas quem seria o destinatário ou auditório social do discurso interior? Para o Círculo, a enunciação pressupõe um interlocutor, que pode ser real, (estar ali presente), ou 'virtual' (nosso termo), como "representante médio do grupo social ao qual pertence o locutor". Assim, a palavra "é função da pessoa desse interlocutor" (e de sua avaliação) ou do 
auditório social (BAKHTIN, 1999, p. 112). Mas além desse interlocutor que pertence a um grupo social, com todas as implicações decorrentes da hierarquia social e laços que os unem, bem como das "pressões sociais", existe um "horizonte social definido e estabelecido que determina a criação ideológica do grupo social e da época a que pertencemos [...]" (ibid., p. 112). Porém, existe ainda a ideologia do cotidiano, que também acompanha nossos atos e "estados de consciência" (ibid., p. 118). Portanto, é o contexto social imediato e o ambiente social mais amplo que determinam a estrutura do enunciado (ibid., p. 113), sua forma estilística e estrutura gramatical.

Bakhtin enfatiza que o "grau de consciência, de clareza, de acabamento formal da atividade mental é diretamente proporcional ao seu grau de orientação social" (ibid., p. 114). E mais, essa orientação social possui um "caráter apreciativo". Toda tomada de consciência é marcada por uma entoação interior que é prolongada ou esclarecida na expressão exterior, mas em função da situação social e do contexto social imediato (ou virtual). Além do destinatário e sub-destinatário (destinatário interior), Bakhtin (2000, p. 356) menciona ainda o sobredestinatário (o terceiro, "cuja compreensão responsiva absolutamente exata é pressuposta seja num espaço metafísico, seja num tempo histórico afastado". O locutor não pode confiar apenas em seus destinatários próximos, pressupondo sempre esse 'terceiro' invisível que se situa acima dos participantes no diálogo.

Mas essa compreensão responsiva ativa, que implica uma contrapalavra (BAKHTIN, 1999, p. 132), já é dialógica (BAKHTIN, 2000, p. 350). A compreensão é, pois, "prenhe de resposta", fazendo com que o destinatário torne-se locutor. Além disso, toda enunciação possui uma orientação apreciativa. O Círculo critica, pois, a distinção entre conotativo (apreciação) e denotativo (significação objetiva), aspecto retomado por Ducrot ao tratar da argumentação na língua. A significação objetiva, afirma Bakhtin (1999, p. 135), "forma-se graças à apreciação; ela indica que uma determinada significação objetiva entrou no horizonte dos interlocutores - tanto no horizonte imediato como no horizonte social mais amplo de um dado grupo social". E a mudança de significação é, na verdade, uma reavaliação; o deslocamento de uma palavra de um contexto apreciativo para outro; o alargamento do horizonte apreciativo, envolvendo contradição, reconstrução.

Outro aspecto relevante em relação ao discurso interior é a discussão sobre o "discurso de outrem". Bakhtin (1999, p. 144) afirma que "[o] discurso citado é o discurso no discurso, a enunciação na enunciação, mas é, ao mesmo tempo, um discurso sobre o discurso, uma enunciação sobre a enunciação" (ênfase do autor); tema autônomo que "torna-se tema de um tema".
Bakhtin aponta a interação entre o discurso interior e a apreensão dos enunciados de outrem (BAKHTIN, 1999, p. 146), pois indica "[...] as tendências sociais estáveis características da apreensão ativa do discurso de outrem que se manifestam nas formas da língua". Essa apreensão está, pois, relacionada à valoração, ela é apreciativa (ou seja, expressa uma posição emotivo-valorativa; um juízo de valor). A entonação expressiva é, pois, "uma particularidade constitutiva do enunciado" (BAKHTIN, 2000, p. 315).

A entonação (que também é determinada pela situação e o auditório social), afirma Voloshinov (1981, p. 304), possui, pois, papel principal na construção do enunciado, pois the confere "seu sentido geral, sua significação global". Uma mesma expressão pode ter sentidos diferentes e indicar valorações diferentes a depender da entonação. E, junto com a entonação, todo o corpo se investe: os movimentos, os gestos, a mímica. Em conjunto, eles expressam a avaliação do locutor.

Existe ainda outra face do discurso interior. A atividade mental é um "território social" e, desde seu início, mesmo em forma ainda confusa, tende a uma expressão externa, à sua materialização. E, após materializada, a palavra atua sobre a atividade mental: "ela põe-se então a estruturar a vida interior, a dar-lhe uma expressão ainda mais definida e mais estável" (ibid., p. 118). Assim, não é a expressão que é orientada pelo mundo interior, mas o contrário: é "o nosso mundo interior que se adapta às possibilidades de nossa expressão, aos seus caminhos e orientações possíveis" (ibid., p. 118, ênfase do autor). Embora tais reflexões estejam relacionadas aos sistemas ideológicos, elas ajudam a compreender a importância da FP no processo de aprendizagem, pois a expressão materializada (o movimento da palavra voltando-se sobre o sujeito) possibilita essa ação reversa na elaboração mental e permite que algo que era vago, confuso, possa ser (re)estruturado.

A expressividade, porém, também está relacionada aos enunciados de outros sobre o mesmo tema; a esses respondemos ou com eles polemizamos. "A mais leve alusão ao enunciado do outro confere à fala um aspecto dialógico [...]" (BAKHTIN, 2000, p. 320). Entretanto, Bakhtin (ibid., p. 355) inclui ainda outro aspecto em relação ao todo do enunciado: ele "não possui uma significação, mas um sentido (um sentido total relacionado com um valor: a verdade, a beleza, etc.; que implica uma compreensão responsiva, comporta um juízo de valor). A compreensão responsiva de um todo verbal é sempre dialógica", visto que o sentido só se estabelece em relação com outros sentidos. Mas o sentido só pode ser apreendido face às circunstâncias, ao contexto, aos eventos, às causas sociais em que um enunciado é proferido; somente se conhecermos sua parte extraverbal. 
Só assim uma pequena exclamação como “Ah!”, poderá ser compreendida como surpresa, indignação, raiva, deleite etc. Ela possui uma significação determinada, que podemos 'transformar' em uma frase bem desenvolvida, clara e completa (VOLOSHINOV, 1981, p. 301-302).

Voloshinov (ibid., p. 302) resume três aspectos sub-entendidos que constituem a parte extraverbal do enunciado e que permitem que as interações verbais sejam possíveis e inteligíveis: 'o espaço e o tempo do evento, o objeto ou tema do enunciado (aquilo do que se fala) e a posição dos interlocutores em relação ao evento (“a avaliação")', resumidos como situação. São, pois, as diferentes situações que determinam que uma mesma expressão adquira diferentes sentidos.

Pensando, pois, no dialogismo, nas múltiplas vozes que comparecem num enunciado, nas palavras de outrem que podem ser ouvidas em nossos enunciados, a Teoria Polifônica da Enunciação (na qual nos inspiramos livremente), que exporemos brevemente a seguir, permite que ao menos algumas dessas vozes e segmentos trazidos de outros contextos não sejam apenas inferidos. Partindo do princípio de que sempre existe ao menos um ponto de vista (lugar valorativo) que se expressa em cada enunciado, permite, ainda, perceber a relação entre diferentes perspectivas e o posicionamento do Locutor, bem como se movimenta, ou seja, como reelabora, transforma, altera, complementa etc., ao dialogar com outras vozes.

\section{Teoria Polifônica da Enunciação}

Partindo das discussões do Círculo, e opondo-se, pois, à noção de unicidade do sujeito falante, Ducrot leva a noção de polifonia para os enunciados. Discordando de uma concepção veritativa de linguagem e da significação, propõe uma concepção instrucional da significação (cf. DUCROT, 2001), com base no conceito de polifonia, que "leva a descrever o sentido do enunciado como uma espécie de diálogo cristalizado" ou a apreender seu sentido por meio da descrição da enunciação, ou seja, evidenciando a confrontação de vozes ali presente (pois um enunciado sempre coloca em cena certo número de personagens). Além disso, sua ideia fundamental é que a frase possui indicações sobre as relações entre os interlocutores.

Para o autor, a argumentação está inscrita, marcada na língua, visto que o poder argumentativo de um enunciado não é determinado somente por seu conteúdo, mas também por sua forma lingüística. Não apenas a frase possui uma orientação argumentativa, mas as próprias palavras. Desta forma, para Ducrot a argumentação não está nos fatos, ela está marcada, inscrita na língua, pois “(...) la forma lingüística misma impone ciertas argumentaciones y no otras" (ibid., p. 77).
Todo enunciado (que expressa sempre ao menos um ponto de vista) é argumentativo, ou seja, é orientado para uma conclusão. Porém, como lembra Banks-Leite (2008), por que há (ao menos) um ponto de vista em cada enunciado? "Porque no enunciado já existe também, intrinsecamente, um valor axiológico. $\mathrm{O}$ valor axiológico marca a subjetividade na linguagem, a não neutralidade, a não objetividade, a não informatividade, etc." Não se traça uma distinção entre aspectos objetivos, subjetivos e intersubjetivos (vinculados à relação locutor/interlocutor). "Mesmo nas palavras do léxico encontra-se esse valor axiológico", observa Banks-Leite. Ou seja, mesmo uma só palavra pode apresentar um ponto de vista.

A união, pois, dos aspectos subjetivo e intersubjetivo resulta no "valor argumentativo" (o conjunto das possibilidades ou impossibilidades de continuação discursiva que determina), isto é, a orientação que determinada palavra dá ao discurso, exigindo que se continue de determinada forma e não de outra; os encadeamentos discursivos possíveis. De acordo com Ducrot (1988, p. 14), falar é “(...) construir y tratar de imponer a los otros una especie de aprehensión argumentativa de la realidad". Não se trata de negar a existência do aspecto informacional, mas este é secundário, derivado do aspecto argumentativo. $\mathrm{O}$ aspecto axiológico, valorativo, tem primazia sobre o informativo, descritivo, referencial.

Mas voltemos às vozes. Para Ducrot, as vozes presentes no enunciado possuem status lingüísticos diferentes. O sujeito que fala possui funções diferentes, a saber, o sujeito empírico (SE - que está relacionado com as condições externas da produção), o locutor (L - o autor do enunciado, responsável por esse e que nele deixa marcas, como a de primeira pessoa, mas que nem sempre é o SE, podendo inclusive ser inanimado) e o enunciador (E). Assim, o Locutor e o Enunciador são figuras discursivas presentes no enunciado (e não os seres no mundo). O autor (ibid., p. 19) afirma que para a lingüística contemporânea, notadamente a francesa, "todo enunciado presenta un cierto número de puntos de vista relativos a las situaciones de las que se habla (...)" e esses pontos de vista diferentes ou perspectivas (e não pessoas diferentes) seriam representados pelos Enunciadores.

Temos, pois, três elementos ligados ao sentido. O primeiro é a apresentação dos pontos de vista pelos enunciadores. O segundo, é que a enunciação pode atribuir ao locutor diferentes atitudes (ou pontos de vista) em relação aos enunciadores, diferentes formas e graus de adesão ou não adesão (DUCROT, 2001), sendo que Ducrot distingue quatro: (1) ele pode se identificar com um dos Enunciadores, tentando impor um ponto de vista, ou seja, o Enunciador é seu porta-voz; (2) pode dar sua aprovação a um Enunciador, mesmo que o enunciado não 
objetive admitir aquele ponto de vista; (3) pode opor-se ao Enunciador, refutando seu ponto de vista, mesmo sem apresentar outro ponto de vista para corrigir o primeiro; (4) pode considerar o Enunciador como objeto de desejo, de crença, etc. Por fim, o terceiro elemento do sentido é a assimilação de um enunciador a uma pessoa $X$, de dar indicações sobre a identidade dos enunciadores. O locutor pode assimilar os enunciadores a diferentes seres (a si mesmo, a um grupo de pessoas, ao interlocutor, a pessoas fora da situação de interlocução, sabedoria popular etc.).

Ducrot (1988) afirma que para encontrarmos a significação da estrutura " $X$ mas $Y$ ", por exemplo, precisamos ter em mente algumas consignas: (1) construir 4 enunciadores, onde $\mathrm{E}_{1}$ contém o ponto de vista $\mathrm{X} ; \mathrm{E}_{2}$ tira uma conclusão $r$ com base em $\mathrm{X} ; \mathrm{E}_{3}$ mantém o ponto de vista $\mathrm{Y}$ ("mas...") e $\mathrm{E}_{4}$ conclui não-r a partir de $\mathrm{Y}$; (2) encontrar a posição do Locutor em relação a esses 4 enunciadores, apontando que este geralmente refuta $E_{2} \mathrm{e}$ se identifica com $\mathrm{E}_{4}$, ou seja, sempre conclui não-r.

Desta forma, observar cada enunciado dialogicamente, como Ducrot o faz, permite uma análise mais rica das mobilizações e movimentações realizadas pelo sujeito (e no sujeito, já que a linguagem e o outro agem sobre este).

De forma semelhante a Ducrot, Goulart também se apóia no Círculo e parte do pressuposto de que "enunciar é argumentar", tema do próximo tópico.

\section{Argumentação e Bakhtin}

A argumentação é concebida como uma atividade social e discursiva, caracterizada pela constituição, negociação e transformação de sentidos. Neste trabalho partimos de uma concepção ampla de argumentação, como aponta Banks-Leite (2010), concebida como a "intervenção sobre as ideias, opiniões, atitudes, sentimentos ou comportamentos de alguém ou de um grupo (GRIZE, 1992, p. 5)", afastando-nos da ideia de que a controvérsia é sua característica essencial. Ao refletirmos sobre a produção de sentidos, sobre a constituição ou elaboração de conhecimento, a controvérsia ou pontos de vista opostos não são condição necessária para que mudanças aconteçam ou para a emergência do novo. A explicitação dos conhecimentos no entrechocar de enunciados leva não apenas à elaboração de conhecimento, mas pode também possibilitar a própria transformação do objeto de discurso, salienta Banks-Leite.

Para melhor compreendermos então o pressuposto de Goulart $(2007,2009)$ de que "enunciar é argumentar" e a influência do destinatário ou do auditório na escolha dos recursos linguísticos e dos procedimentos composicionais adotados pelo locutor, retomemos alguns pontos do Círculo. O enunciado é sempre uma resposta a outros enunciados e, ao mesmo tempo em que aguarda, presume ou antecipa uma resposta, busca avaliar o fundo aperceptivo do auditório ou do interlocutor. Isso, por sua vez, influencia o próprio enunciado em relação ao seu conteúdo temático, à escolha do gênero de discurso (ou sua forma composicional) e à seleção dos recursos linguísticos (o estilo) (BAKHTIN, 2000, p. 321). Acreditamos, portanto, que Bakhtin deixa já implícita a característica argumentativa dos enunciados, a começar pela própria concepção de "signo ideológico" (ou seja, não neutro). Como bem lembra Authier-Revuz (2004, p. 35-36), retomando Bakhtin,

\footnotetext{
Toda palavra "remete a um contexto, ou a vários, nos quais viveu sua existência socialmente subjugada". Ela "chega a seu próprio contexto, vinda de outro contexto, penetrada pelo sentido dado por outros". As palavras são "carregadas", "ocupadas", "habitadas", "atravessadas" por discursos, é o que Bakhtin designa "saturação da linguagem [...] socialmente significante [...] por intenções e acentos determinados".
}

Mas a argumentatividade também pode ser percebida quando Bakhtin (2002, p. 183) explica as relações dialógicas, "inclusive as relações dialógicas do falante com sua própria fala" e evidencia que dentro de um enunciado haverá tal relação se percebermos aí a voz de outra pessoa. Sendo, ainda, cada enunciado uma resposta a outros enunciados, ou um diálogo que se estabelece (mesmo à distância no tempo/espaço) com outros enunciados, seja refutando, complementando ou se apoiando neles, "[n]ão podemos determinar nossa posição sem correlacioná-la com outras posições" (BAKHTIN, 2000, p. 316). Cada enunciado, portanto, conforme propõe Ducrot, evidencia ao menos um ponto de vista; sempre assumimos uma posição valorativa em relação às palavras de outrem.

Desta forma, a compreensão responsiva ativa expressa a posição valorativa do locutor; comporta um juízo de valor (assumir um ponto de vista), que, ao entrar em contato com a palavra do outro não fica inalterada. Assim, "[c]ompreender não deve excluir a possibilidade de uma modificação, ou até de uma renúncia, do ponto de vista pessoal" (BAKHTIN, 2000, p. 382), podendo, ainda ser "o fortalecimento pela fusão" (BAKHTIN, 2000, p. 350), a concordância e ampliação de uma perspectiva. Podemos, pois, a partir das discussões de Bakhtin e, concordando com Goulart (2007, p. 97) que se ancora na natureza dialógica da linguagem, conceber que "enunciar é argumentar", propondo que enunciar é agir sobre o outro. Assim, ao adotarmos uma atitude responsiva ativa em relação às palavras de outrem, esta envolve "simpatia, concordância, discordância, estímulo à ação" (BAKHTIN, 2000, p. 310), etc., ou seja, envolve sempre 
um juízo de valor, um tom apreciativo. Goulart (2009) salienta que o enunciado é tão orientado (em uma direção) que já contém o germe da resposta, possui uma intenção. É por essa razão que é argumentativo. Os enunciados são sempre grávidos de sentidos e são sempre intenção, complementa.

Os processos argumentativos se manifestam, por exemplo, na retomada ou estranhamento da palavra do outro, no tom apreciativo. Também as linguagens sociais, continua Goulart (2007, p. 95), “implicam, além do vocabulário, formas de orientação intencional de interpretação, com direções definidas [...]". Goulart retoma ainda, a questão do conflito em nosso interior referente aos diferentes pontos de vista, diferentes tendências e avaliações ali presentes, além da questão da palavra de autoridade e do valor que a sustenta, em contraposição à palavra internamente persuasiva. Acreditamos que as considerações aqui tecidas forneçam as bases para conceber a argumentatividade na FP, que buscamos evidenciar no dado analisado.

\section{Análise do Dado}

Como conceber a atividade de um sujeito que, ao responder, se ouve falando, se interrompe, hesita, distancia-se do que diz, analisa sua fala, traz enunciados de outros, antecipa uma contrapalavra? O outro irrompe nos enunciados dos alunos de várias formas, não se reduzindo ao outro dos sentidos cristalizados, do interdiscurso, dos estereótipos etc. Esse movimento desvela a atividade dialógica, a pluralidade de vozes que participam na constituição do conhecimento e que foram capturadas utilizando-se o paradigma indiciário (GINZBURG, 1989) e a análise microgenética, destacando-se as pistas deixadas pela atividade epilinguística (GERALDI, 1991).

\section{Sinais de transcrição:}

\author{
Alunos: PA, MA, GU. \\ Professora: $\mathbf{T}$. \\ Pausas: / (um sinal para cada segundo) \\ Prolongamento do som: : \\ Comentários do pesquisador: (( )) \\ Fala sobreposta: [
}

\section{Descrição:}

Neste episódio, os alunos jogavam um jogo em que, com base em cartões contendo cenas de atividades do cotidiano (que iam retirando de uma pilha), faziam uma pergunta a um colega que, por sua vez, deveria responder usando uns dos cartões de advérbio de freqüência que havia sorteado. A professora colocou no quadro-negro alguns exemplos contendo a estrutura que seria usada no jogo. Após a primeira rodada do jogo, ela decide então fazer outra rodada, em que um aluno perguntaria ao outro sobre um terceiro, enfocando a 3 a pessoa do singular. Antes de proceder à nova fase, alguns exemplos foram praticados e então eles continuaram entre eles. É neste ponto que iniciamos nosso recorte.

(1) T: OK / MA ((dando-lhe os cartões)) you choose one and ask Okay?

(2) MA: Ah:

(3) T: The same way I was doing.

(4) MA: perguntá de alguém pra alguém?

(5) T: Yeah Yeah

(6) MA: Uhm / Seboso ((examinando um dos cartões)) // Não / péraí ((escolhe outro cartão)) /// Seboso / How often / eh / how often / do / (olha para o quadro negro) como que eu coloco uma pessoa ali fssora?

(7) T: How often? // Guys? ((solicitando que os colegas ajudem)) How often?

(8) PA: GU / perguntá de mim pra outra pessoa?

(9) T: ((acena afirmativamente)) e o auxiliar?

(10) MA: É então é do GU / mas aí fica estranho não é fssora? ((olha para o quadro negro, onde a professora havia colocado o exemplo de perguntas, mas usando 'you')) // How often ele ((olhando para o quadro negro formula a frase gesticulando, indicando com a mão levantada no ar na altura do rosto o local das palavras em sua frase que vai sendo escrita no ar)) / ((olha de volta para a professora)) então é do you / do GU / mas aí fica estranho ((olha para o quadro novamente))

(11) MA: É então é do GU / mas aí fica estranho não é fssora? // How often ele / então é do you / do GU / mas aí fica estranho

(12) GU: Do he?

(13) MA: Não

(14) PA: Não How often Gustavo do you

(15) MA: Então do you / ((olhando para PA)) Não GU 'do' GU daí fica estranho professora não é não? / nada a vê não ((abaixa a cabeça))

(16) PA: Com que freqüência o $\mathbf{~ G U}$

(17) MA: É

(18) GU: pensa assim / [se fosse / se fosse / se fosse assim T: Qual é o auxiliar pra he e she?

(20) MA: É ‘do’ mesmo é ‘do' GU mas fica estranho não é não? / A:h does GU / do GU fica estranho does GU / [How often does GU: / How often does GU / brush the teeth / teeth? T: OK 
Iniciamos expondo o 'pano de fundo' da enunciação, em que verificamos a inter-regulação da atividade e os modos de participação do aluno. Primeiramente, ele é instado pelo professor a se engajar em um jogo. Temos, assim, a autoridade e poder do professor, que diz ao aluno o quê/como fazer e aos quais supostamente ele deve aceder. Em outro plano, temos a autoridade das regras do jogo (outros enunciados, outras vozes atuando), a nosso ver, em duas 'dimensões': regras explícitas: as regras do jogo em si, que já implicam o tipo de pergunta e resposta esperados, trazendo, em decorrência, regras implícitas: num movimento dialógico, o aluno antecipa que o professor espera que use determinada estrutura e se conforme à norma culta da LE. Assim, nesse contexto, as regras do jogo assumem novas significações ligadas a uma regra geral (não explicitada): "temos que usar a norma padrão da LE". Ou seja, além da autoridade do professor e do 'peso' de não poder ou querer errar, temos também as regras ou a autoridade da estrutura da língua.

A atividade do aluno é regulada por essas (e outras) regras ou prescrições explícitas ou implícitas, que remetem à sua história educacional. E é nesse breve espaço de tempo (para nós, observadores), que vemos se condensar as múltiplas e variadas vozes (e perspectivas) dispersas no tempo e no espaço. O continuum espaço-tempo se expande para MA, desenvolvendo-se uma variedade de conflitos, reflexões, confrontos, deliberações, em uma única unidade de tempo (o enunciado).

Contudo, há aqui um elemento complicador: parte das regras explicitadas na primeira rodada do jogo foi modificada e, embora alguns exemplos tenham sido trabalhados, esses não foram suficientes para que as mudanças fossem percebidas. Houve o deslocar de um jogo para "outro jogo". Temos, pois, a regra antiga "Do you" (escrita no quadro-negro e ainda lá presente, dialogando com o jogo) e a nova regra (implícita) "Does he". E é aí que se instaura a tensão, verificada no fio discursivo.

O jogo é interrompido e o foco torna-se o funcionamento da língua. Ao tentar elaborar a pergunta, MA depara-se com um problema. Observamos que ele hesita (/ How often / eh / how often / do / (olha para o quadro negro) como que eu coloco uma pessoa ali fssora?) e isso o faz raciocinar em voz alta. Ele diz "How often" e 'trava'. Não conseguindo continuar, busca apoio na autoridade presente: a professora. Já que esta não o ajuda, só pode recorrer à autoridade incorporada no quadro-negro. No turno 7 a professora intervém, tentando indicar a organização do conhecimento. Sua intervenção, no entanto, não o ajuda. E é nesse ponto que observamos que ao mesmo tempo em que se dirige a seu interlocutor (a professora), não apenas verificamos (por intermédio de seus gestos, direcionamento do olhar, da atividade epilinguística) que existe um trabalho de deliberação sendo realizado no âmbito do discurso interior (que 'vaza' parcialmente), onde outras vozes se fazem ouvir. Como afirma França (2006), 'outros "personagens" aguardam silenciosos o momento em que se tornará possível fazê-los vir à tona do enunciado verbalizado'.

Seguindo o pensamento do Círculo, poderíamos dizer que nossas reflexões somente avançam no diálogo com outros interlocutores, não num movimento de oposição, mas no entrechocar de diferentes perspectivas. E aqui vemos que MA parece discordar que o modelo no quadro-negro se aplique a essa nova rodada do jogo, colocando em diálogo diferentes pontos de vista. MA dialoga com seu(s) destinatário(s) interiores e a professora, envolvendo, ainda, seus colegas. Evidencia, assim, que para resolver sua dúvida, precisa colocar em confronto (e não em oposição) diferentes perspectivas. Isso constitui, a nosso ver, a riqueza desse dado.

No entanto, o processo de reflexão de MA, a tentativa de resolução da dúvida não se limita a esse segmento, evidenciando o entrelaçamento entre o discurso interior e a fala externalizada. Vemos aqui os diferentes diálogos que o sujeito trava; a tensão entre exterioridade/interioridade, pois o sujeito dialoga 'consigo mesmo' ao mesmo tempo em que dialoga com o outro. E o outro, ao ouvi-lo, não apenas lhe responde, mas também dialoga 'consigo mesmo': se interroga, se questiona, reflete, tenta elaborar. Por essa razão, portanto, enfocaremos todo o evento, no qual podemos observar dois movimentos (1) a linguagem enquanto atividade, trabalho (do sujeito e sobre o sujeito) e (2) a atividade dialógica, ambas imbricadas.

O retorno de MA sobre seu próprio dizer (comentando sua própria fala), seu distanciamento em relação a ele, revela pontos de não coincidência interlocutiva, de não coincidência do sujeito com seu próprio dizer (a modalidade autonímica, AUTHIER-REVUZ, 2004); indica a alteridade, a presença do outro. Tentando, pois, apreender o outro nessa fala, buscaremos examinar os diferentes enunciadores (diferentes perspectivas ou pontos de vista) que são convocados nesse enunciado, utilizando os quatro enunciadores descritos por Ducrot.

$\mathrm{E}_{1}$ : (tomado aqui como representando, para os alunos, a posição da professora por intermédio de seus exemplos escritos no quadro negro): A forma adequada a ser usada com 'GU'é 'DO'

$\mathrm{E}_{2}$ : Então é 'do you do $G U$ ' (conclusão $r$, a partir do que foi apresentado por $\mathrm{E}_{1}$ )

$\mathrm{E}_{3}$ : Mas aí fica estranho (aqui o operador 'mas' inverte a orientação do enunciado anterior, conduzindo a uma conclusão não-r $r$ )

$\mathrm{E}_{4}$ : 'DO' não é a forma adequada (a conclusão não-r fica, pois, implícita) 
No primeiro segmento, relativo ao Enunciador $2\left(\mathrm{E}_{2}\right)$ a palavra 'então' introduz uma conclusão e, no encadeamento discursivo, notamos que responde à própria pergunta de MA ("Como é que eu coloco uma pessoa ali fssora? - "ali" indicando o quadro-negro), já que a professora não a respondeu e, ao mesmo tempo, à pergunta da professora ("e o auxiliar?"), tentando evocar sua lembrança de algo que sabe que já aprendeu. No entanto, de onde provém o $\mathrm{E}_{1}$ que afirma que é "do $G U$ '? Nesse ponto, são as evidências extratextuais (o olhar de MA dirigindo-se ao quadro-negro, por exemplo) que permitem responder a essa questão. $\mathrm{E}_{1}$ se baseia nos exemplos no quadro-negro trazendo, assim, a voz/ posição/ponto de vista da professora. Ou seja, $E_{1}$ pode ser assimilado à perspectiva da professora, que orienta para determinada conclusão. Poderíamos colocar assim: "Se os exemplos que temos para nos basear e que a professora mesma colocou no quadro, contêm ' $D o$ ', conseqüentemente, 'Do' é o que devemos usar aqui". Assim, assume-se que o "novo jogo" segue a mesma estrutura usada anteriormente. Desta forma, $\mathrm{E}_{2}$, que aqui pode ser visto como reafirmando a regra da língua que está escrita no quadro, conclui que ' $D O$ ' seria usado também para a terceira pessoa do singular.

Porém, ao iniciar o novo segmento com "mas" (uma espécie de vedete do discurso persuasivo, segundo Ducrot, 2003), MA introduz outro Enunciador (E3), que orienta a uma conclusão não-r. Assim, assimilando-se a E4, MA conclui que "Do GU" não é a forma apropriada. Nesse movimento, não temos evidências das vozes que comparecem ou que MA convoca, mas podemos inferir que MA se baseia em algo já lido ou ouvido anteriormente, ou seja, apóia-se em seu conhecimento prévio (outros enunciados, outras vozes). MA conclama, ainda (na forma de interrogativa, "não é fssora?"), o ponto de vista de outro enunciador, o da própria professora.

Vemos que MA tenta elaborar a pergunta usando o quadro-negro como referência, já que a professora não respondeu sua pergunta. Inicialmente MA busca o ponto de vista da professora ("não é fssora?"). Ao fazê-lo, convoca outro enunciador (ou uma espécie de mediador). Devido ao segmento tratar-se de uma interrogativa, assemelha-se também ao "Terceiro" que Plantin (1999) menciona, com sua atitude interrogativa ou como a figura do cético radical. O 'terceiro', no entanto, não se posiciona. Desta forma, sem outro tipo de apoio, MA dialoga com os exemplos que a professora (a autoridade) havia colocado no quadro-negro, que seriam os vestígios restantes de uma autoridade que não se posiciona frente a seu conflito. No entanto, aquela formulação não soa correta. Porém, sendo a professora que o disse, então DEVE estar correto. Em quem confiar? $\mathrm{Na}$ autoridade ou em sua intuição? Está instaurado um ciclo conflituoso que vai se repetindo: confiar em si ou na autoridade? Dizer algo esperando por uma confirmação ou correção? Se autopreservar ou correr o risco de ser repreendido pela professora? Dizer algo inapropriado e aprender aquilo que não sabe, desacreditando a 'resposta' inicial?

É interessante observar que MA retoma o segmento '(ai) fica estranho', sete vezes, o que salienta seu dilema. Ao mesmo tempo, em cinco instâncias ele usa o operador 'mas', evidenciando o aspecto adversativo, disjuntivo, a não coincidência interlocutiva. Apresenta também um ponto de vista valorativo (que remete a uma comunidade de falantes). Mas embora tenhamos uma mesma frase, se tomarmos tal segmento como parte de um enunciado, os sentidos não são sempre os mesmos, pois se estabelecem na relação dialógica entre enunciados e isso é demonstrado na entonação de MA. Ao mesmo tempo, em relação ao todo do enunciado, implica que sua compreensão dessa questão, ou seu posicionamento em relação ao questionamento que propôs, vai se alterando. As nuances percebidas na entonação anunciam como ele vai se posicionando. É sempre um novo acontecimento.

MA primeiramente pergunta "mas ai fica estranho não é fssora?". Logo em seguida ele retoma, sendo sua entonação um pouco mais assertiva. Depois novamente retoma seu dizer, perguntando e afirmando, respectivamente. No turno 15 esse processo se repete, mas de forma um pouco mais categórica, pois MA diz "nada a vê não". Em seguida ele mais uma vez retoma o segmento, convocando a professora. Ela, porém, havia feito uma intervenção e ele consegue finalmente 'ver' o que parecia estranho. Seu " $A: h$ " indica o momento da 'descoberta'. Como afirma Ducrot (1987, p. 175), a interjeição "Ah!” pode ser provocada pela alegria sentida ao se experimentar determinado fato, "explodindo", escapando, pois, na interjeição. Aqui, a 'descoberta' se faz sentir ou "explode" na interjeição.

Em seguida, MA diz 'fica estranho', como uma confirmação de tal descoberta, podendo finalmente confiar em si mesmo, tanto que sua entonação muda, soando assertiva, indicando uma conclusão, uma tomada de posição com segurança. Desta forma, com o apoio da autoridade, pode finalmente negar abertamente o Enunciador 1. Ele então reafirma "Does $G U$ ", como que dando um fechamento a esse episódio.

Ao mesmo tempo, podemos perceber que o conflito se estende a PA e GU, que também não ousam colocar em xeque a autoridade que se faz 'ouvir' no quadro-negro. Eles tentam ajudar o amigo que está 'em apuros' mas acabam sendo engolfados pelo conflito e não conseguem avançar. Porém, nos turnos 13 e 14, MA e PA afirmam que 'não'. Ou seja, parecem julgar que não está correto. Entretanto, assumem seu 'não' somente entre eles, ao tentarem raciocinar em conjunto. O envolvimento de GU e 
PA ao buscarem chegar à formulação adequada evidencia dois aspectos: (1) que a FP, ao emergir em sala de aula e ser ouvida pelos outros provoca uma atitude responsiva ativa, ou seja, deixa de ser somente para o próprio sujeito; (2) que pode dar lugar à atividade conjunta de elaboração de conhecimento.

Observamos, também, como o objeto de conhecimento vai sendo construído (enquanto objeto-dediscurso), por meio dos 'tateamentos' (Banks-Leite, 2010), da exploração dos alunos e das diferentes vozes convocadas em seus enunciados, revelando um processo argumentativo em que não se tem uma posição definida ou estável de antemão e busca-se defendê-la e refutar outras, mas que a argumentação está relacionada a ideias, objetos, posições, que ainda estão sendo co-construídos, estão em curso de elaboração (no espaço dialógico, discursivo).

Podemos perceber, portanto, as diferentes posições no enunciado de MA. Entretanto, os interlocutores não se resumem àqueles ali presentes nem aos que MA convoca, nem às regras explícitas e implícitas que expusemos. Existem outros interlocutores (incluindo os artefatos culturais) e outros enunciados que vão regulando a participação desses alunos que são decorrentes de suas experiências escolares. Aparentemente, como alunos, pensamos: "Não posso errar"; "A professora sabe que eu já aprendi isso, então..."; "O professor disse $\mathrm{X}$, não posso contestar", etc. Todas essas possíveis considerações, esses vários enunciados estavam provavelmente 'pipocando' no discurso interior de MA e o impactaram.

\section{Conclusão}

Vimos, pois, neste episódio, a elaboração sendo realizada discursivamente, no embate de palavras e vozes, no revolver sobre as palavras, sobre a objetivação material da palavra, como algo que não existia antes de ser trabalhado nas/pelas palavras, no encontro entre diferentes vozes. Vimos os alunos se distanciarem do evento, o observar de outro(s) ponto(s) de vista. Sua perspectiva (posição) se altera e eles passam a se observar, refletir, analisar suas (re)ações. Porém, apenas essa mudança de posição não é suficiente, é preciso um interlocutor (mesmo que seja no discurso interior). Isso implica ocupar topologicamente outra posição, outro centro de perspectiva (que significa buscar o apoio, a perspectiva de outros: sub-destinatário, comunidade social, horizonte social, sobredestinatário).

Vimos também MA se engajar em um processo argumentativo. Ele parece desempenhar dois papéis argumentativos (proponente e oponente), mas, na verdade, ele coloca em cena diferentes perspectivas e tenta refletir sobre elas, já que (como vemos no final do episódio) ele não está se opondo ao ponto de vista que ele mesmo está tentando assumir. Esse processo culmina com uma resposta, onde verificamos não uma revisão de perspectiva, ou a reformulação ou mudança de posição, mas uma tomada decisiva de posição que antes não ousava. Ele finalmente assume a posição que vinha anunciando desde o princípio, pois se assimilava desde então a $E_{4}$, embora temerariamente. Nesse processo vimos os movimentos de comparar, ponderar, aceitar ou não a palavra do outro, retomá-la, ampliá-la ou modificála etc., contribuindo para a elaboração do conhecimento.

\section{Referências}

AUTHIER-REVUZ, J. Entre a transparência e a opacidade: um estudo enunciativo do sentido. Porto Alegre: EDIPUCRS, 2004.

BAKHTIN, M. M. Problemas da poética de Dostoiévski. 3. ed. Rio de Janeiro: Forense Universitária, 2002[1929].

BAKHTIN, M. M. (VOLOSHINOV). O Freudismo. Tradução Paulo Bezerra. São Paulo: Perspectiva, 2001[1927].

BAKHTIN, M. M. (VOLOSHINOV). A estética da criação verbal. 3. ed. São Paulo: Martins Fontes, 2000[1979].

BAKHTIN, M. M. (VOLOSHINOV, V. N.) Marxismo e filosofia da linguagem. 9. ed. Tradução Michel Lahud e Yara Frateschi Vieira. São Paulo: Hucitec, 1999[1929].

BANKS-LEITE, L. Discours argumentatif en classe d'histoire: stéréotypes et construction de connaissances. In: BRANDT, P.-Y et al. (Orgs.). Des signes et des ordres: hommage à Christiane Gillièron Paléologue. Genebra: Labor et Fides, 2010. p. 35-45.

BENVENISTE, É. Problemas de Lingüistica Geral II. 2. ed. Campinas: Pontes, 2006[1974].

DUCROT, O. (2003). Argumentação retórica e argumentação linguística. Tradução de R. L. Baronas e F. C. Montanheiro. Revista Polifonia. Cuiabá: UFMT, 2004.

DUCROT, O. Quelques raisons de distinguer "locuteurs" et "énonciateurs". Polyphonie - linguistique et littéraire, n. 3, p. 19-41, maio 2001.

DUCROT, O. Polifonia y argumentación. Cali, Colombia: Impresora Feriva, 1988.

GERALDI, J. W. Portos de passagem. 2. ed. São Paulo: Martins Fontes, 1991.

GINZBURG, C. Mitos, emblemas e sinais. São Paulo: Cia das Letras, 1939/1989.

GOULART, C. M. A. Enunciar é argumentar: analisando um episódio de uma aula de História. Revista Pro-Posições (Unicamp), v. 18, n. 3(54), p. 93-108, set.-dez. 2007.

GOULART, C. M. A. Aprendizagem, conhecimento e linguagens sociais. Palestra proferida na FE/Unicamp, no Ciclo de Palestras "Linguagem, Discurso e Conhecimento", sob organização do GPPL (Grupo Pensamento e Linguagem), 23 abr. 2009.

GRIZE, Jean-Blaise. Argumenter, prouver et calculer. In: RACCAH, P. Y. L'argumentation dans le langage. Gent: Communication \& Cognition, 1992. p. 13-19. 
PEYTARD, J. Discours intérieur vs discours rapporté chez Volochinov/Bakhtine. Hétérogénéité en discours. Cahiers du français contemporain, n. 3 (juin), p. 9-26, 1996.

PIAGET, J. A linguagem e o pensamento da criança. 7. ed. São Paulo: Martins Fontes, 1999[1966].

VOLOSHINOV, V. N. [1926]. Discurso na vida e discurso na arte. Tradução de Carlos Alberto Faraco e Cristovão Tezza, para uso didático, com base na tradução inglesa de I. R. Titunik ("Discourse in life and discourse in art - concerning sociological poetics"). In: VOLOSHINOV, V. N. Freudism, New York: Academic Press, 1976.
VOLOSHINOV, V. N. La structure de l'enoncé. In: TODOROV, T. Mikaïl Bakhtine - le principe dialogique, suivi de Ecrits duCercle de Bakhtine. Paris: Seuil, 1981, p. 287-315.

VYGOTSKY, L. V. A. Pensamento e Linguagem. São Paulo: Martins Fontes, 1987[1934].

VYGOTSKY, L. V. Manuscrito de 1929 [Psicologia Concreta do Homem]. Educação e Sociedade, v. 21, n. 71, p. 21-44, 2000.

Recebido: 25 de agosto de 2015

Aprovado: 20 de novembro de 2015

Contato: mktostes@uol.com.br 